\title{
Governments urged to back Internet use
}

Snekkersten, Denmark. Political leaders from 27 industrialized countries last week took the first steps towards greater international collaboration to encourage and regulate the growth of the use of the Internet for research.

The move came at a conference on the "Global Research Village", organized by the Organization for Economic Cooperation and Development (OECD), and chaired by Frank Jensen, Denmark's minister of research and information technology.

Much of the two-day meeting - which was held near Helsingør, the Elsinore of Shakespeare's Hamlet - was spent debating the role that governments could and should play in developing research networks. "Governments haven't yet defined their role," argued Michael Oborne, the OECD's deputy director for science technology and industry, at the opening session.

Two broad areas of consensus emerged. The first was the need for governments to ensure that the research community has an adequate networking infrastructure by resolving the current congestion on the Internet and lowering research networks' operating costs (see Nature 380, 377; 1996).

The second was that international agreements harmonizing legal, regulatory and commercial practices are needed to ensure that the Internet remains an open system able to contribute to economic growth and social development in all countries, including those in the developing world.

Jensen said that research networks could not rely on commercial expansion and improvement of the Internet. Public investment is needed to give researchers the infrastructure they need, he said, adding that governments should facilitate the development of high-speed research networks.

But the appropriate form of government intervention was hotly debated at the meeting. Robert Cailliau, director of the World Wide Web at the European Laboratory of Particle Physics (CERN) argued that, while government researchers still need funding to pay for their access to the Internet, financing of the extra bandwidth needed on the network will not come from government but from expansion of commercial services.

Other delegates argued, however, that governments could usefully provide funding to pump-prime new developments, such as the US National Science Foundation's support for new high-speed backbones (see Nature 380, 93; 1996). Furthermore, one delegate said, cooperation between OECD governments on providing adequate links between existing networks is insufficient.

Several delegations also insisted that liberalization of telecommunications is a prerequisite of low-cost research networks. J. M. M. Ritzen, the Dutch minister of education, culture and science, pointed out that Europe's telephone companies charge customers ten times as much for a new service as do their US counterparts.

An even bigger hindrance, he said, is the reluctance of telephone monopolies to meet demand for high-speed connections. OECD governments have "an important part to play in remedying the inadequacies of the telecoms infrastructure that stand in the way of scientific communication", said Ritzen.

José Mariano Gago, Portugal's minister for science and technology, went further, suggesting that research organizations should be required to pay only a fraction of

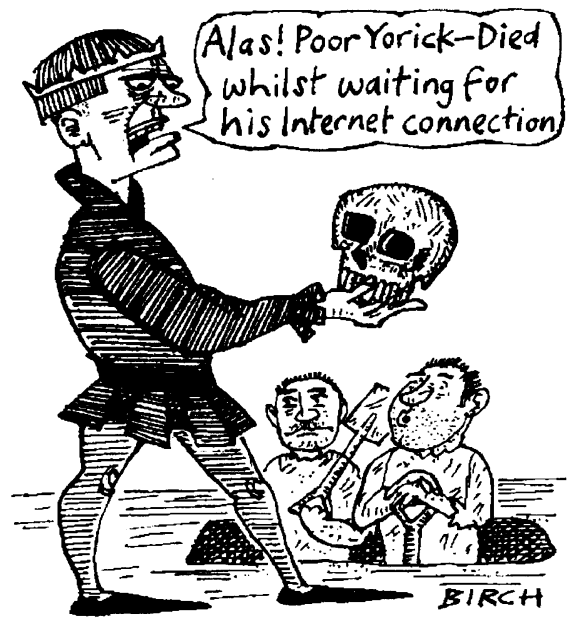

the real operating costs of networks. Jensen said governments have the power to negotiate better conditions from telecommunications operators, pointing out that he has obtained a 65 per cent reduction in the costs of research networks from Danish telecoms.

Another area where OECD governments could usefully cooperate, participants said, is in developing international "legal, regulatory, and commercial regimes". They agreed, for example, that an effective legal framework is needed within existing intellectual property regimes to cover issues raised in the transfer of scientific information between the public and private sector.

One result of the lack of international agreement on legal issues is that, under contracts from some US telecommunications companies, European research networks could, in principle, be sued if any of their researchers use their US links to access pornographic sites.

Indeed, Cailliau said that while he had originally opposed greater government control of the Internet, he now feels this was needed to bring greater order. Issues such as preventing criminal use of the Web require internationally binding agreements, he said. "A happy village is not on the cards unless politicians make it happen," said Pat Rabbitte, Ireland's minister of commerce, science and technology.

The meeting also strongly recommended that OECD governments support the development of virtual electronic research libraries and the digitization of research documents. Such libraries, it said, should be open to all researchers worldwide, both in the public and private sectors.

To promote greater collaboration between industry and academic institutions, the meeting also said that OECD countries should explore the setting up of international "virtual research centres of excellence" and the use of networks to provide better access to expensive science facilities.

Meanwhile, many delegates expressed concern that the flexibility offered by electronic publishing risks reducing the quality of scientific information, and with it the reputation of the scientific community. The meeting unanimously supported the need to maintain high standards of quality assurance in electronic publishing.

But while agreeing that peer review should be the principal means of doing so, it also said that governments should "explore" the need to subsidize the setting up of 'e-print' archives in all disciplines.

Although the 'Elsinore agenda' agreed at the end of the meeting merely represents its conclusions and does not imply any commitment on the part of the governments represented, Jensen says it is a first step towards putting research and the Internet on the political agenda.

Declan Butler

\section{Germany gears up for high-speed network}

Munich. After years of lagging behind its neighbours, Germany is about to become the second country in Europe to offer its scientists a national, very-highspeed broad-band data network.

Next month, data transmission on the newly established national broadband scientific network, called B-Win, which links around 50 university departments and research institutes, will be increased in speed from 34 megabits to 155 megabits per second.

In the past, delays in modernizing

communications systems have caused Germany many problems. In 1993, for example, it lost a bid to host the European Bioinformatics Institute, an outstation of the Heidelberg-based European Molecular Biology Laboratory, partly because of its poor electronic datalinks (see Nature 361, 383; 1993).

B-Win is run by the Deutsche Forschungsnetz, an organization based in Berlin and similar to UKERNA, a British body which operates the UK academic network JANET. Quirin Schiermeier 